\title{
Optimal Control of PID-FUZZY based on Gravitational Search Algorithm for Load Frequency Control
}

\author{
Habib Danaeefar, Hasaan Barati, Seyyed Arman Shirmardi \\ Department of Electrical and Computer Engineering, \\ Islamic Azad University Dezful Branch, \\ Dezful, Iran
}

\begin{abstract}
In this paper, an efficient and effectual optimization algorithm called Gravitational Search Algorithm (GSA) is suggested to optimally tune the PIDFUZZY parameters toward accurate frequency control of two-area power system. An effective and precise optimization algorithm i.e., GSA has been constructed based on the gravity law and mass interactions. In this algorithm, the explorer operators are a masses collection which interacts with each other according to the motion laws and Newtonian gravity. To appropriately and accurately confirm the dynamic performance of suggested GSA-based PID-Fuzzy, four performance indexes, i.e.: ISE, ITSE, IAE and ITAE have been considered as objective functions. Furthermore, the simulations results by the suggested GSAbase PID-FUZZY have been compared with the simulation results based on Particle Swarm Optimization (PSO) and Artificial Bee Colony (ABC) algorithms which are generally realized as conventional heuristic algorithms and extensively applied by the researchers and scholars. Finally, optimal GSA-based PID-FUZZY presents a high dynamic performance as compared to PSO-based PID-FUZZY and ABC-based PID-FUZZY.
\end{abstract}

Keywords: Power system dynamic stability, low frequency oscillation, automatic generation control, optimization algorithms, gravitational search algorithms.

\section{INTRODUCTION}

The value of consumed power around the world exhibits the state of the art level of countries that shows the importance of power quality, voltage regulation and system frequency stability issues. That is to say, all criterions of power quality have been studied and analyzed on frequency and voltage of power system. Since the system frequency control is highly longer than the voltage control, it is regarded as salient benchmark in the power system. Thus, system frequency stability should be principally investigated and involved in many researches and projects [1]. Integration of many different power sources or areas has constructed the interconnected power system. Any power variations in power source and load which happen in these areas can disturb other connected areas. The tie-line characteristic between these areas is one other important item in impressing the frequency stability. During the high variations in system frequency which go beyond the defined limits, they can create severe power system instability, which will stop the connected power plants and even shut down the entire system in the later step. In this instance, the fed areas of the system remain without energy and cause vast economic damages [2]. Consequently, considering these vast economic damages due to system collapse, the frequency control of loads is regarded a salient problem which must be considered to hinder such damages.

Automatic Generation Control (AGC) has decreased the deviations of tie-line power and frequency in order to swiftly restore its nominal frequency [3-5]. The conventional controller such as: classical Proportional Integral Derivative (PID) controller has been widely used for AGC in interconnected power systems. But, this controller cannot effectively suppress the fluctuations tie-line power and frequency during severe perturbations. Considering the benefits of PID controller, it has been integrated with Fuzzy controller to construct PID-Fuzzy controller aimed at suppression of low frequency oscillations. As reported in various literatures, Fuzzy controller provides good performance during the normal, unbalance and transient conditions [6-8]. The parameters of PID-Fuzzy can be tuned in real time in accordance with load perturbations to enhance its accuracy and robustness toward acquiring the best control aims.

In recent years, the evolutionary optimization algorithms such as Bacteria Foraging (BF), Particle Swarm Optimization (PSO) and Artificial Bee Colony (ABC), Ant Colony Optimization (ACO) have been widely used by researchers to solve the various objective functions in different problems [9-13]. Although aforementioned algorithms seem to be excellent to optimally tune the parameters of controller, they introduce a slow convergence with local minimums. Gravitational Search Algorithm (GSA), a new evolutionary optimization algorithm, presents a fast convergence and accurate performance in these aspects [14-16]. In this regard, it is applied to optimally tune the parameters of PID-Fuzzy for stabilizing the interconnected power system.

In this study, the parameters of PID-Fuzzy have been tuned by GSA, PSO and ABC so that its performances can be well compared and appraised. The relevant studies have been performed in two-area interconnected power system. Severe load perturbation has affected the interconnected power system to deal with the dynamic stability criterions with presence of PID-FUZZY. Finally, optimal GSA-based PIDFUZZY presents a high dynamic performance as compared to PSO-based PID-FUZZY and ABC-based PID-FUZZY. 


\section{INTERCONNECTED POWER SYSTEM STRUCTURE}

Kinetic and potential energy has been transformed into mechanical energy using turbines, following that, the mechanical energy has been transformed into electrical energy using power plant's generators. Simple motion equation based on the mentioned concept can be presented by:

$T_{m}-T_{e}=J \frac{d \omega}{d t}$

Where, $T_{m}$ and $T_{e}$ are respectively mechanical and electrical torque. $J$ and $\omega$ are respectively the inertia and angular speed.

The understudy power system contains two interconnected areas via tie-line. Note that, all available generators in each area have a combined construction. Occurrence of any perturbations in each area of power system leads to frequency deviation in other areas. Then, this deviation creates fluctuation in tie-line power. In this regard, both the tie-line power and frequency deviations must be damped to maintain the dynamic stability of interconnected power system. The tie-line power can be presented by:

$P_{\text {line } 12}=\frac{\left|V_{1}\right| \cdot\left|V_{2}\right|}{X_{12}} \sin \left(\delta_{1}-\delta_{2}\right)$

Where, $V_{1}$ and $V_{2}$ are respectively voltage of first and second areas. $\delta_{1}$ and $\delta_{2}$ are respectively machine angle of first and second areas. $\mathrm{X}_{12}$ indicates tie-line impedance. The machine angle deviation of each area can be presented by:

$\Delta \delta=2 \pi \int \Delta f d t$

The tie-line power deviation can be presented by:

$\Delta P_{12}=\frac{\left|V_{1}\right| \cdot\left|V_{2}\right|}{X_{12}} \cos \left(\delta_{1}-\delta_{2}\right)\left(\Delta \delta_{1}-\Delta \delta_{2}\right)$

Where, the synchronous coefficient is written as follows:

$T_{12}=\frac{\left|V_{1}\right| \cdot\left|V_{2}\right|}{X_{12}} \cos \left(\delta_{1}-\delta_{2}\right)$

The tie-line power deviation is rewritten by:

$\Delta P_{\text {tie }}=T_{12}\left(\Delta \delta_{1}-\Delta \delta_{2}\right)$

Thereupon load deviation $\Delta P_{L}$, tie-line power deviation, frequency deviation and Area Control Error (ACE) of each area can be given by following equations:

$$
\begin{gathered}
\Delta P_{\text {tie }}=\frac{-\Delta P_{L 1}\left(\frac{1}{R_{2}}+D_{2}\right)}{\frac{1}{R_{1}}+\frac{1}{R_{2}}+D_{1}+D_{2}} \\
\Delta f=\frac{-\Delta P_{L 1}}{\frac{1}{R_{1}}+\frac{1}{R_{2}}+D_{1}+D_{2}} \\
A C E_{1}=\Delta P_{t i e}+B_{1} \cdot \Delta f_{1} \\
A C E_{2}=B_{2} \cdot \Delta f_{2}+a_{12} \cdot \Delta P_{\text {tie }}
\end{gathered}
$$




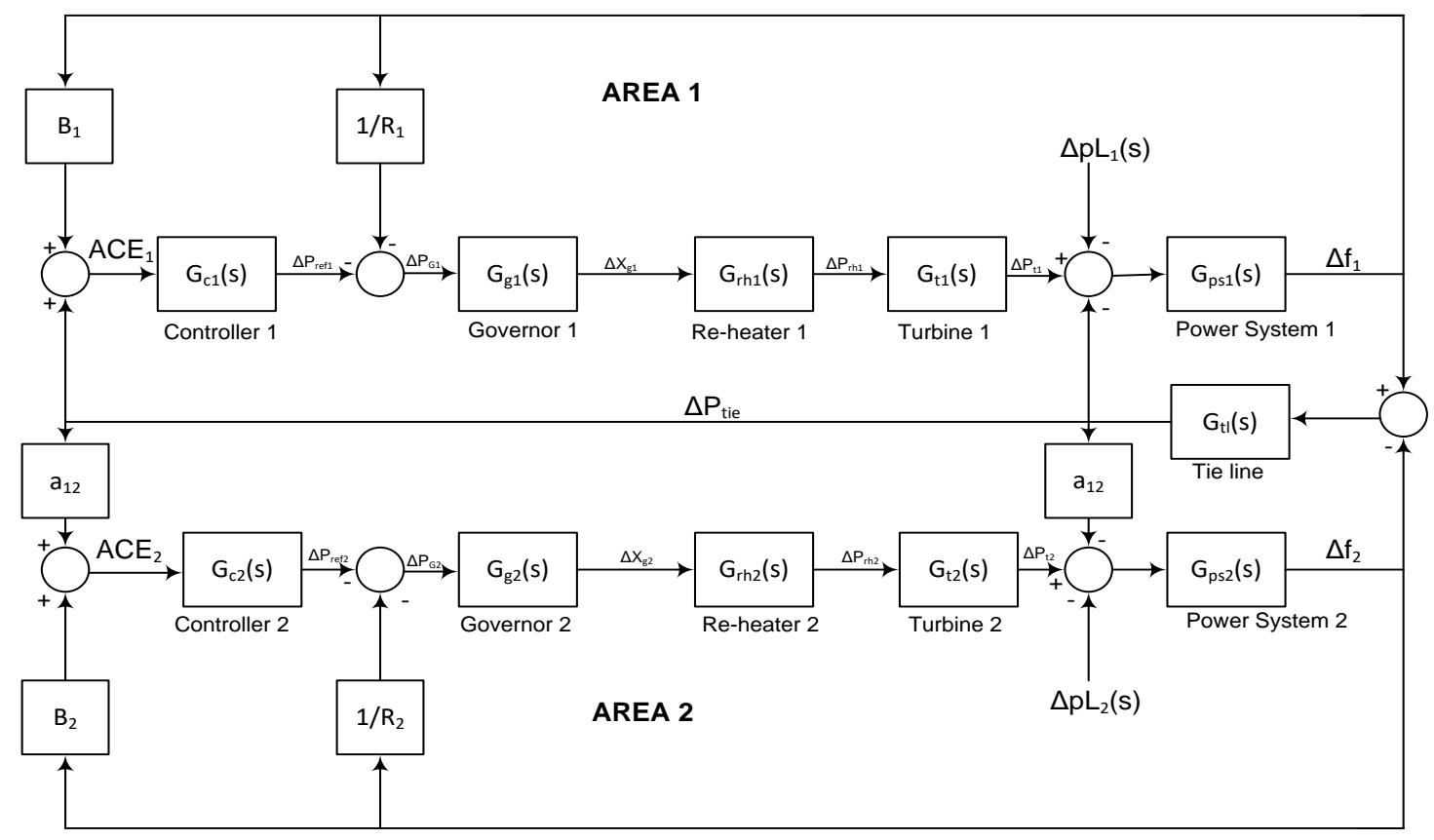

Figure 1. Two-area interconnected power system

Figure 1 presents the linearized model of two-area interconnected power system. The following equations give the transfer function of each block:

\section{Governor:}

$G_{g 1}(s)=G_{g_{2}}(s)=\frac{K_{h}}{T_{h} \cdot s+1}$

Reheater:

$G_{r h 1}(s)=G_{r h 2}(s)=\frac{\left(\mathrm{K}_{\mathrm{r} 12} \cdot \mathrm{T}_{\mathrm{r} 11}\right) \cdot s+1}{T_{r 1} \cdot s+1}$

Turbine:

$G_{t 1}(s)=G_{t 2}(s)=\frac{\mathrm{K}_{\mathrm{t}}}{T_{t} \cdot s+1}$

Power system:

$G_{p s 1}(s)=G_{p s 2}(s)=\frac{\mathrm{K}_{\mathrm{g}}}{T_{g} \cdot s+1}$

Tie-line:

$G_{t l}(s)=\frac{2 \pi \cdot \mathrm{T}_{12}}{s}$

The understudy two areas of interconnected power system are thermal plant. Rate of each area is 2000 MW with 1000 MW (nominal load). This system has been widely studied in different literatures which propose, design and analyze the required controller for AGC to enhance the power system dynamic stability [17-19].

\section{CONSTRUCTION OF PID-FUZZY CONTROLLER}

A PID-Fuzzy controller enhances the dynamic performance of PID controllers, because Fuzzy logic can appropriately control the changes in parameters of power systems or operating point via auto-tuning gains of PID controller [20]. Precise design of Fuzzy controller has been performed by choosing an appropriate membership functions and rule formulation. So, general membership functions and rules have been selected for input/output while the parameters of PID controller can be optimally tuned to enhance the overall dynamic performance of PID-Fuzzy controller [21]. Twodimensional rule base PID-Fuzzy controller has been designed by the error signal along with its derivative for input signal PID controller for output signal [22. As mentioned above, PID-Fuzzy controller which is shown in Fig. 2 (a) is designed for AGC to enhance the dynamic performance of power system. $K_{1}$ and $K_{2}$ are input gains of PID-Fuzzy controller while $\mathrm{K}_{\mathrm{P}}, \mathrm{K}_{\mathrm{I}}$ and $\mathrm{K}_{\mathrm{D}}$ are its output gains. The fuzzy rules and its input membership function are respectively presented in Table 1 and Fig. 2(b).The membership functions are defined by: PB (Positive Big), PM (Positive Medium), PS (Positive Small), ZE (Zero), NS (Negative Small), NM (Negative Medium) and NB (Negative Big) as fuzzy measure. 
Fuzzy Logic Controller

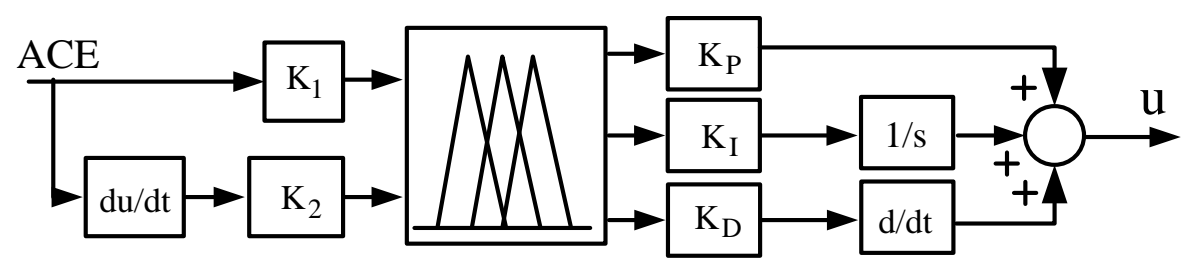

Figure 2(a). PID-Fuzzy controller model

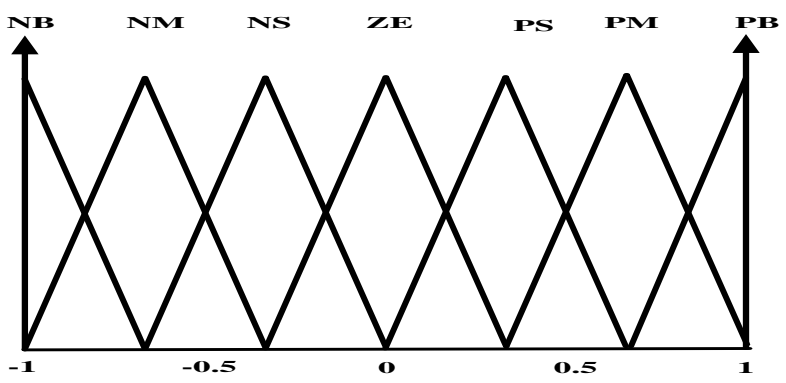

Figure 2(b). Normalized membership function for inputs

Table 1. Lookup table of fuzzy rules

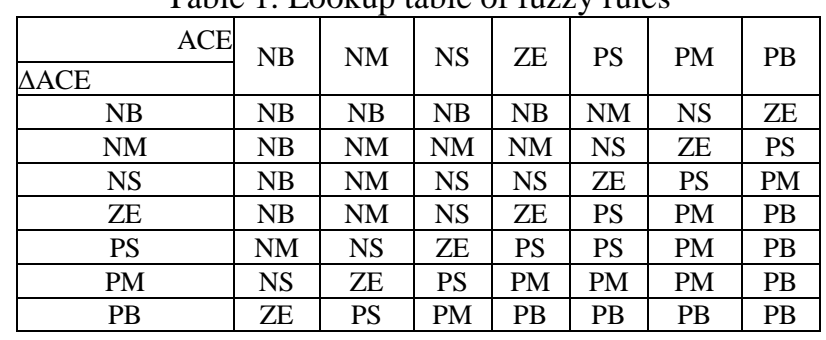

\section{GRAVITATIONAL SEARCH ALGORITHM}

GSA is a heuristic stochastic evolutionary algorithm proposed by Rashedi et al in 2009 [17]. It is inspired by the mass interactions and gravitation newton principle. All objects are absorbed by a gravitational force, which forces all objects to move toward heavy masses as shown in Fig. 3(a). It exhibits a natural behavior between earth and the moon. The weightiest object suggests the problem solution. The Flowchart of GSA process is given in the Fig. 3(b), and also its general Pseudo code is provided in Fig. 3(c). According to GSA procedure, each mass includes four statements: position, inertial mass, active gravitational mass, and passive gravitational mass [18]. The mass position related to the problem solution, and its gravitational and inertial masses have been defined via an objective function. That is to say, each mass gives a result that GSA is navigated via correct tuning the gravitational and inertia masses [19]. By time span, it is expected that masses to be pulled by the weightiest mass which gives an optimal response in the search space.
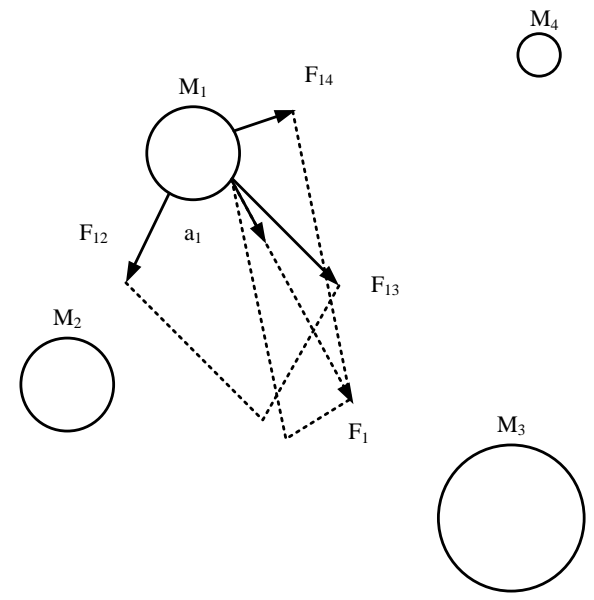

Figure 3(a). Every mass accelerate towards to the resultant force 

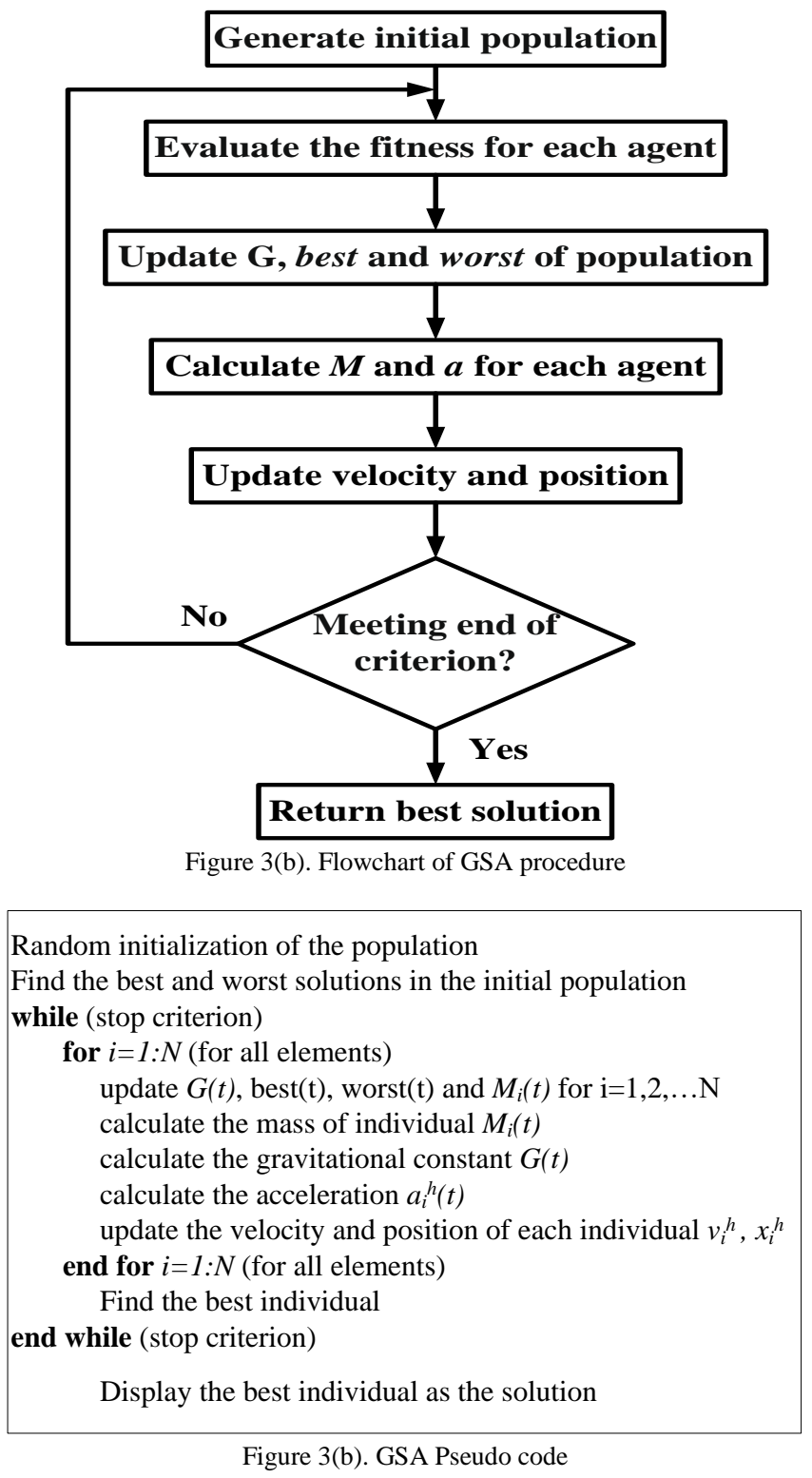

\section{SIMULATIONS AND RESULTS}

The performance of control systems has been assessed based on an especial performance index depends on the required objective function. The performance index is alternatively used to design of controllers which are commonly known by: integral of squared error (ISE), integral of time multiplied squared error (ITSE), integral of

$$
\begin{aligned}
& I S E=\int_{0}^{T}\left\{\Delta F_{1}^{2}+\Delta F_{2}^{2}+\Delta P_{t i e, 12}{ }^{2}\right\} \cdot d t \\
& I T S E=\int_{0}^{T}\left\{\Delta F_{1}^{2}+\Delta F_{2}^{2}+\Delta P_{t i e, 12}{ }^{2}\right\} \cdot t \cdot d t \\
& I A E=\int_{0}^{T}\left\{\Delta F_{1}|+| \Delta F_{2}|+| \Delta P_{t i e, 12} \mid\right\} \cdot d t \\
& I T A E=\int_{0}^{T}\left\{\left|\Delta F_{1}\right|+\left|\Delta F_{2}\right|+\left|\Delta P_{\text {tie, }, 12}\right|\right\} \cdot t \cdot d t
\end{aligned}
$$

absolute error (IAE) and integral of time multiplied absolute error (ITAE) [23-25]. To appropriately and accurately confirm the dynamic performance of suggested GSA-based PID-Fuzzy, all aforementioned have been taken into account for designed optimization problem. These objective functions are given as follows: 
The PID-Fuzzy parameters have been optimally tuned by GSA in order to alleviate the tile-line power and frequency deviations. Furthermore, the controller parameters have been optimized by PSO and ABC to more validate the dynamic performance of GSA-based PID-Fuzzy controller. The operational constraints of controller parameters are given as follows:

$K_{1}^{\min } \leq K_{1} \leq K_{1}{ }^{\max }$

$K_{2}{ }^{\min } \leq K_{2} \leq K_{2}{ }^{\max }$

$K_{P}^{\min } \leq K_{P} \leq K_{P}^{\max }$

$$
K_{I}^{\min } \leq K_{I} \leq K_{I}^{\max }
$$

$K_{D}^{\min } \leq K_{D} \leq K_{D}^{\max }$

In the simulations, a step load perturbation occurs in first area of the interconnected power system to affect the dynamic stability. The optimization problem has been performed with GSA, PSO and ABC considering all chosen performance indexes. The load perturbation occurs at $\mathrm{t}=10 \mathrm{~s}$ with $\Delta \mathrm{P}_{\mathrm{L}}=0.01$. The optimal parameters of PID-Fuzzy controller optimized by GSA, PSO and $\mathrm{ABC}$ are tabulated in Table 2. Meanwhile, the values of defined performance indexes, i.e.: ISE, ITSE, IAE and ITAE are presented in Table 3. Also, three stability benchmarks i.e.: settling time, overshoot and undershoot are tabulated in Table 4.Both the time-varying frequency and tie-line power deviations are respectively presented in Fig. 4(a-c).

Table 2. The parameters of PID-Fuzzy optimized by GSA, PSO and ABC

\begin{tabular}{|l|l|l|l|l|l|l|}
\hline & \multicolumn{2}{|c|}{ GSA } & \multicolumn{2}{c|}{ ABC } & \multicolumn{2}{c|}{ PSO } \\
\hline & Area 1 & Area 2 & Area 1 & Area 2 & Area 1 & Area 2 \\
\hline $\mathbf{K}_{\mathbf{1}}$ & 1.1854 & 1.6210 & 1.5021 & 1.8428 & 1.8029 & 2.2367 \\
\hline $\mathbf{K}_{\mathbf{2}}$ & 0.5649 & 0.7431 & 0.6712 & 0.9142 & 0.8291 & 1.0056 \\
\hline $\mathbf{K}_{\mathbf{P}}$ & 0.6094 & 0.7885 & 0.7003 & 0.9462 & 0.9906 & 1.2049 \\
\hline $\mathbf{K}_{\mathbf{I}}$ & 0.7951 & 1.0359 & 0.9615 & 1.3410 & 1.2986 & 1.372 \\
\hline $\mathbf{K}_{\mathbf{D}}$ & 0.4932 & 0.6372 & 0.58960 & 0.7743 & 0.5765 & 0.9211 \\
\hline
\end{tabular}

Table 3. The optimal value of dynamic performance indexes achieved by GSA, PSO and ABC

\begin{tabular}{|l|l|c|c|}
\hline $\begin{array}{l}\text { Parameter } \\
\text { indexes }\end{array}$ & GSA & ABC & PSO \\
\hline ISE & 2.7025 & 4.0962 & 4.7643 \\
\hline ITSE & 0.1496 & 0.1924 & 0.2241 \\
\hline IAE & 2.5618 & 3.4577 & 3.9553 \\
\hline ITAE & 71.7942 & 110.4983 & 130.3509 \\
\hline
\end{tabular}

Table 4. The optimal value of dynamic performance indexes achieved by GSA, PSO and ABC

\begin{tabular}{|l|c|c|c|}
\hline $\begin{array}{l}\text { Stability } \\
\text { benchmarks }\end{array}$ & GSA & ABC & PSO \\
\hline Overshoot & 0.0116 & 0.0148 & 0.0156 \\
\hline Undershoot & 0.0192 & 0.01984 & 0.0208 \\
\hline Settling time & 55.31 & 62.12 & 68.76 \\
\hline
\end{tabular}

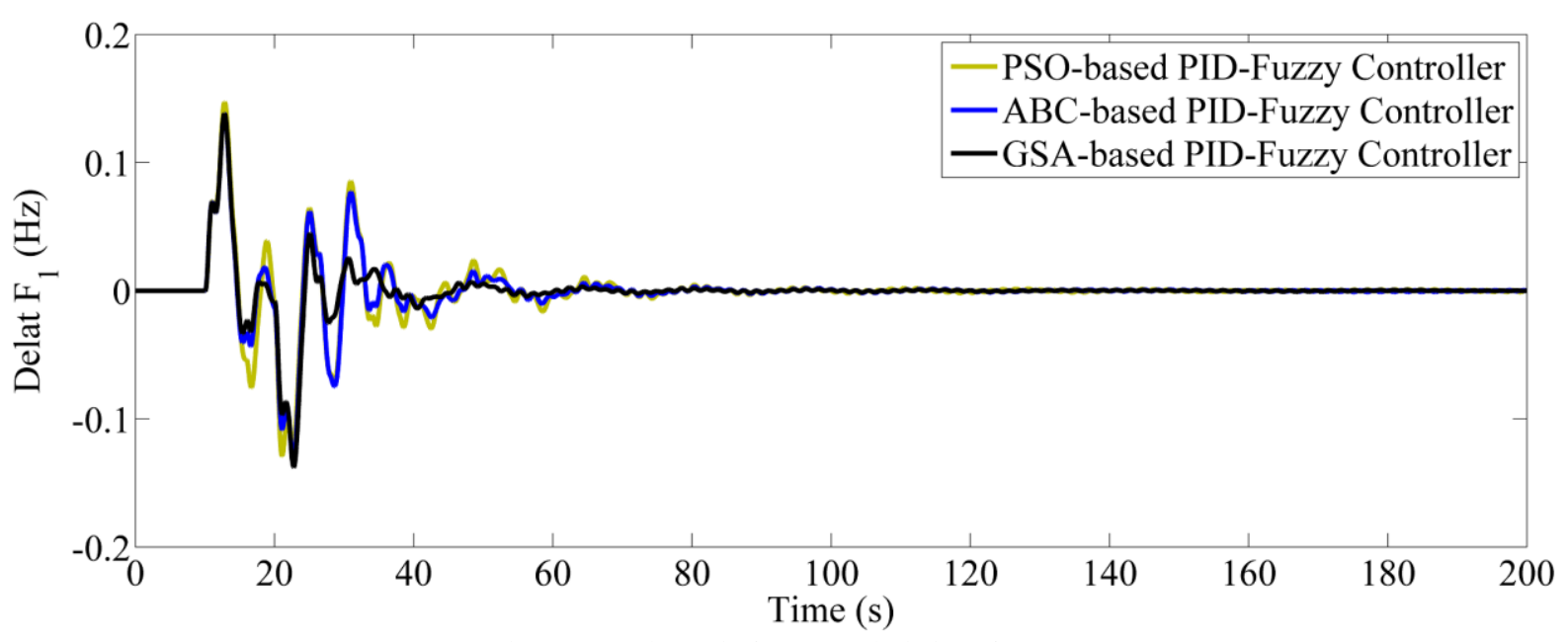

Figure 4(a). Change in frequency deviation of area-1 


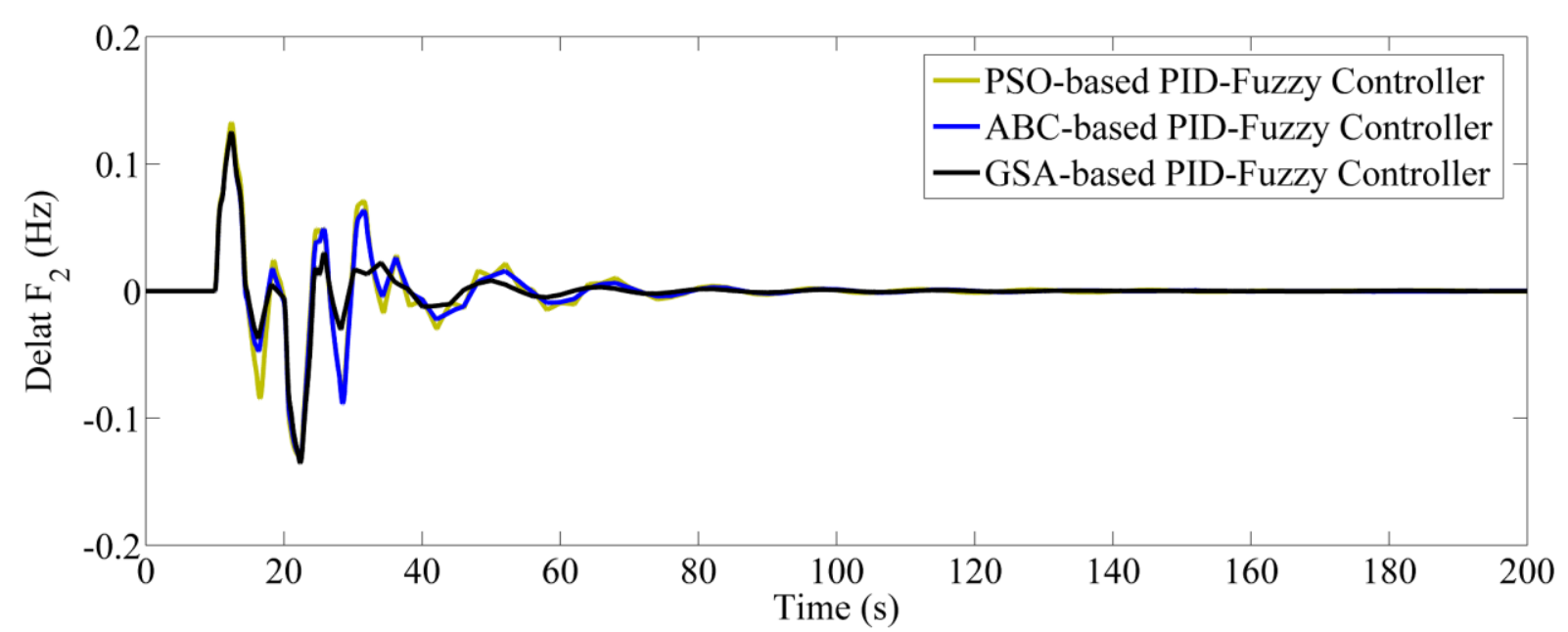

Figure 4(b). Change in frequency deviation of area-2

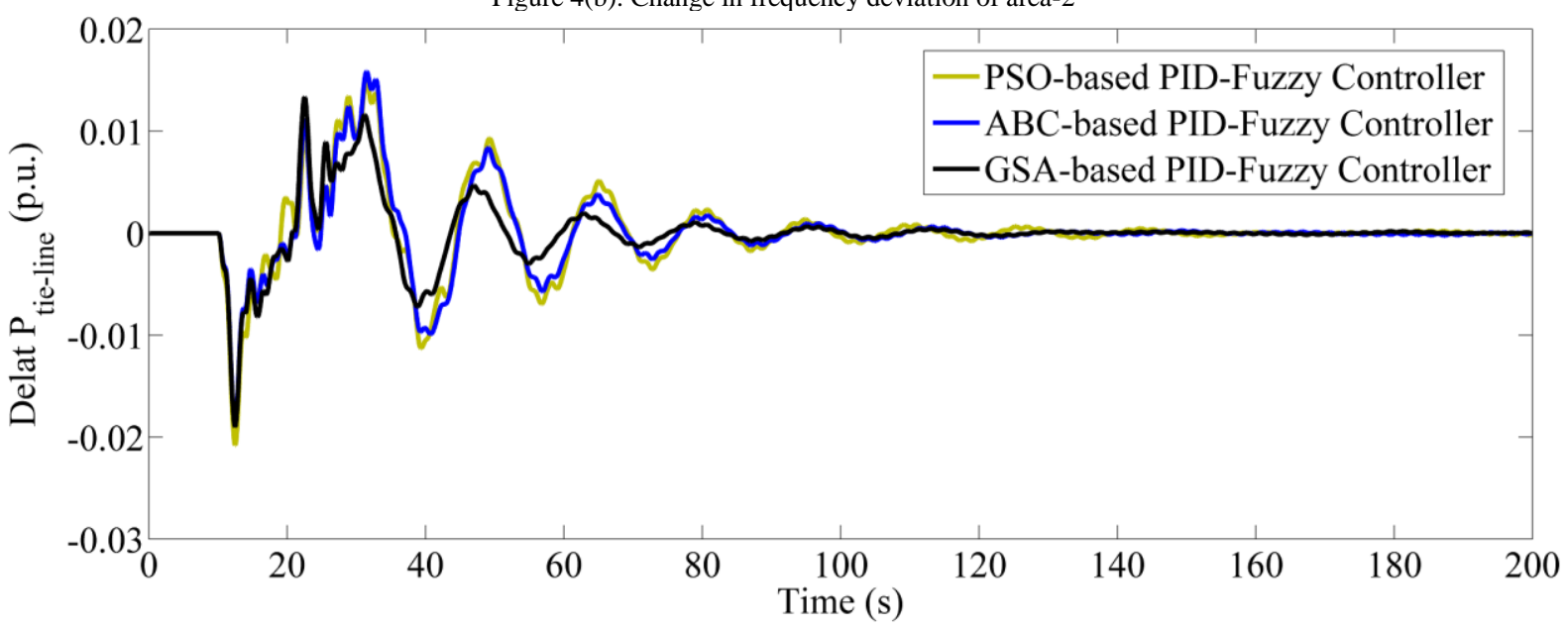

Figure 4 (c). Change in tie-line power deviation between area-1 and area-2

As for the Table 2-4, all performance indexes optimized by GSA present less values as compared to corresponding indexes optimized by PSO and ABC. The presented results prove that the overall dynamic stability of interconnected power system has been highly improved by GSA-based PIDFuzzy more than two others. The time-varying curves presented in Fig. 4(a-c) have better portrayed the dynamic performance of GSA-based PID-Fuzzy.

\section{CONCLUSION}

In this paper, PID-Fuzzy controller is suggested for AGC appropriately enhance the dynamic stability of two-area interconnected power system. GSA algorithm has been complementary applied to optimize the parameters of PIDFuzzy so that its maneuverability to be increased. Hence, PSO and ABC have been taken part in optimization problem to clear the accuracy and capability of GSA. Dynamic stability analysis has been more carried out with consideration of four performance indexes i.e.: ISE, ITSE, IAE and ITAE. The pertinent dynamic stability studies have been performed by affecting the interconnected power system caused by load perturbation occurrence in area-1. Eventually, the simulation results confirm the high dynamic performance of GSA-based PID-Fuzzy via damping the low frequency oscillations of tie-line power and frequency deviations.

\section{REFERENCES}

[1] Kundur, P. Power system stability and control, 8th reprint. New Delhi: Tata McGraw-Hill; 2009.

[2] M.T. Özdemir, D. Öztürk, İ. Eke, V. Çelik, K.Y. Lee, Tuning of Optimal Classical and Fractional Order PID Parameters for Automatic Generation Control Based on the Bacterial Swarm Optimization, IFAC-Papers On-Line 2015, Vol. 48, No. 30, pp. 501-506.

[3] S.P. Ghoshal, Multi-area frequency and tie-line power flow control with fuzzy logic based integral gain scheduling, The Institution of Engineers (India)-Technical Journals: Electrical Engineering, 2003, Vol. 84, pp. 135-141.

[4] J. Morsali, K. Zare, M.T. Hagh, MGSO optimized TID-based GCSC damping controller in coordination with AGC for diverseGENCOs multi-DISCOs power system with considering GDB and GRC non-linearity effects, IET Generation, Transmission \& Distribution, 2017, Vol. 11, No. 1, pp. 193 - 208.

[5] K. Zare, M.T. Hagh, J. Morsali, Effective oscillation damping of an interconnected multi-source power system with automatic generation control and TCSC, International Journal of Electrical Power \& Energy Systems, 2015, Vol. 65, pp. 220-230.

[6] J. Liu. C. Wu, Z. Wang, L. Wu, Reliable filter design for sensor networks in the type-2 fuzzy framework, IEEE Transactions on Industrial Informatics, 2017, Vol. 13, No. 4, pp. 1742-1752.

[7] H. Yousef, Adaptive fuzzy logic load frequency control of multiarea power system, International Journal of Electrical Power \& Energy Systems, 2015, Vol. 68, pp. 384-395. 
[8] N. Ngawong, I. Ngamroo, Intelligent photovoltaic farms for robust frequency stabilization in multi-area, interconnected power system based on pso-based optimal Sugeno fuzzy logic control, Renew Energy, 2015,Vol. 74, pp. 555-567.

[9] B. Mohanty, TLBO optimized sliding mode controller for multiarea multi-source nonlinear interconnected AGC system, International Journal of Electrical Power \& Energy Systems, 2015, Vol. 73, pp. 872-881.

[10] S. Dhillon, J. Lather, S. Marwaha, Multi objective load frequency control using hybrid bacterial foraging and particle swarm optimized pi controller, International Journal of Electrical Power \& Energy Systems, 2016, Vol. 79, pp. 196-209.

[11] A. Rajesekhar, P. Kunathi, A. Abraham, M. Pant, Fractional order speed control of DC motor using levy mutated artificial bee colony algorithm, Proceedings of the World Congress on Information and communication Technologies, Mumbai, 2011, pp. 7-13.

[12] E.S. Ali, S.M. Abd-Elazim, Optimal PID tuning for load frequency control using bacteria foraging optimization algorithm, IEEE 14th international middle east power systems conference (MEPCON 2010), Cairo University, Giza, Egypt, December 2010, pp. 410-5.

[13] M. Omar, M. Soliman, A. Abdel Ghany, F. Bendary, Optimal tuning of PID controllers for hydrothermal load frequency control using ant colony optimization, International Journal on Electrical Engineering and Informatics, 2013, Vol. 5, No. 3, pp.348-360.

[14] M.B. Dowlatshahi, H. Nezamabadi-pour, Ggsa, a grouping gravitational search algorithm for data clustering, Engineering Applications of Artificial Intelligence, 2014, Vol. 36, pp. 114-121

[15] X. Han, L. Quan, X. Xiong, M. Almeter, J. Xiang, Y. Lan, A novel data clustering algorithm based on modified gravitational search algorithm, Engineering Applications of Artificial Intelligence, 2017, Vol. 61, pp. 1-7

[16] C. Li, J. Zhou, J. Xiao, H. Xiao, Parameters identification of chaotic system by chaotic gravitational search algorithm, Chaos, Solitons \& Fractals, 45 (2012), pp. 539-547.

[17] M.R. Sathya, Ansari MT. Load frequency control using bat inspired algorithm based dual mode gain scheduling of PI controllers for interconnected power system. International Journal of Electrical Power \& Energy Systems, 2015, Vol. 64, pp. 365-374.

[18] Y. Arya, AGC of two-area electric power systems using optimized fuzzy PID with filter plus double integral controller, Journal of The Franklin Institute., 2018, Vol. 355, No. 11, pp. 4583-4617.

[19] Y. Arya, Automatic generation control of two-area electrical power systems via optimal fuzzy classical controller, Journal of The Franklin Institute., 355 (5) (2018), pp. 2662-2688.

[20] R.K. Sahu, S. Panda, N.K. Yegireddy, A novel hybrid DEPS optimized fuzzy PI/PID controller for load frequency control of multi-area interconnected power systems, J. Process Control 24 (2014) 1596-1608

[21] K.S. Rajesh, S.S. Dash, Ragam Rajagopal, Hybrid improved fire fl y-pattern search optimized fuzzy aided PID controller for automatic generation control of power systems with multi-type generations, Swarm and Evolutionary Computation, 2019, Vol. 44, pp. 200 211.

[22] A. R. Tavakoli, A. R. Seifi, Adaptive self-tuning PID fuzzy sliding mode control for mitigating power system oscillations Author links open overlay panel, Neurocomputing, 2016, Vol. 218, pp. 146-153

[23] Y. Arya, N. Kumar, Design and analysis of BFOA-optimized fuzzy PI/PID controller for AGC of multi-area traditional/restructured electrical power systems, Soft Computing, 2017, Vol. 21, No. 21, pp. 6435-6452.

[24] Y. Arya, N. Kumar, BFOA-scaled fractional order fuzzy PID controller applied to AGC of multi-area multi-source electric power generating systems, Swarm and Evolutionary Computation, 2017, Vol. 32, pp. 202-218.

[25] D. Guha, P.K. Roy, S. Banerjee, Load frequency control of interconnected power system using grey wolf optimization, Swarm and Evolutionary Computation, 2016, Vol. 27, pp. 97-115. 